\section{Response to: 'Potential roles for tenascin in (very) early diagnosis and treatment of rheumatoid arthritis' by Cutolo et al}

We thank the authors for their commentary ${ }^{1}$ on our article which was recently published in the Annals of Rheumatic Diseases. ${ }^{2}$ Cutolo et al write an extended discussion of the study, in which we describe the development of therapeutic monoclonal antibodies that block the pro-inflammatory activity of the fibrinogen-like globe (FBG) domain of tenascin-C, and the efficacy of these antibodies in preventing disease progression in preclinical models of rheumatoid arthritis (RA). The commentary includes a detailed summary of the autoantibody response to a citrullinated epitope (cTNC5) within the FBG domain of tenascin-C which arises very early during the development of $\mathrm{RA}$, and which can also be detected in around one in five people at risk of developing RA. As highlighted by the authors, the questions around how the response to modified components of the extracellular matrix evolves during the development of RA, and whether or not this autoantibody response contributes to disease pathogenesis, are an area of ongoing research. We also agree that detection of anticitrullinated peptide antibodies recognising cTNC5 in people with RA, or who will go on to develop RA, should be explored as a potential companion diagnostic with which to identify individuals who may benefit from treatment with therapies directed against the FBG domain of tenascin-C. If this hypothesis holds true, then we may well be able to stratify patients in whom we can intervene to stop disease progression from an extremely early stage. Following the seminal paper by Cutolo et al in 1992, ${ }^{3}$ there has been enormous progress worldwide in the field of tenascin- $\mathrm{C}$ and joint pathology. Although there remains much work still to be done, not least in assessing the potential benefits of targeting tenascin- $\mathrm{C}$ as a means to treat people with RA in the clinic, as well as discovering more about whether a direct link exists between the pathogenic action of the FBG domain as a modulator of Toll-like receptor 4-mediated inflammation with its role in adaptive immunity in this disease, these are challenges that we look forward to facing.

Susan Aungier, ${ }^{1}$ Alison J Cartwright, ${ }^{1}$ Anja Schwenzer, ${ }^{1}$ Jennifer Marshall, ${ }^{2}$ Mike R Dyson, ${ }^{3}$ Peter Slavny, ${ }^{3}$ Kothai Parthiban, ${ }^{3}$ Aneesh Karatt-Vellatt, ${ }^{3}$ Ilfita Sahbudin, ${ }^{4,5}$ Eric Culbert, ${ }^{6}$ Patrick Hextall, ${ }^{6}$ Felix IL Clanchy, ${ }^{1}$ Richard Williams, ${ }_{4}^{1}$ Brian D Marsden ${ }_{1,7}^{1,}$ Karim Raza, ${ }^{2,8}$ Andrew Filer, ${ }^{2}$ Christopher D Buckley, ${ }^{1,2}$ John McCafferty, ${ }^{3}$ Kim S Midwood ${ }^{1}{ }^{1}$

${ }^{1}$ Kennedy Institute of Rheumatology, Nuffield Department of Orthopaedics, Rheumatology and Musculoskeletal Sciences, University of Oxford, Oxford, UK ${ }^{2}$ Institute of Inflammation and Ageing, University of Birmingham, Queen Elizabeth Hospital, Birmingham, UK

${ }^{3}$ IONTAS Ltd, Cambridge, UK

${ }^{4}$ Rheumatology Research Group, School of Immunity and Infection, Birmingham, UK

${ }^{5}$ University Hospitals Birmingham NHS Foundation Trust, Birmingham, UK

${ }^{6}$ Nascient, Cambridge, UK

${ }^{7}$ Structural Genomics Consortium, Nuffield Department of Clinical Medicine, University of Oxford, Oxford, UK

${ }^{8}$ Department of Rheumatology, Sandwell and West Birmingham Hospitals NHS Trust, Birmingham, UK
Correspondence to Professor Kim S Midwood, Nuffield Department of Orthopaedics, Rheumatology and Musculoskeletal Sciences, Kennedy Institute of Rheumatology, Oxford OX3 7FY, UK; kim.midwood@kennedy.ox.ac.uk

Handling editor Josef S Smolen

Acknowledgements The authors would like to thank the Technology Hub Imaging Centre at the University of Birmingham.

Contributors All authors reviewed the response.

Funding This work was supported by grants from Nascient Ltd (SRA, AJC, FC and JLM), Arthritis Research UK Fellowships (20003: AS and KSM) and (18547: AF), and an Arthritis Research UK programme grant (19791: CDB). This work was also supported by the Arthritis Research UK Rheumatoid Arthritis Pathogenesis Centre of Excellence (20298). BDM was supported by the SGC and by the Kennedy Trust for Rheumatology Research. This report includes independent research supported by the National Institute for Health Research/Wellcome Trust Clinical Research Facility at University Hospitals Birmingham NHS Foundation Trust.

Disclaimer The views expressed in this publication are those of the author(s) and not necessarily those of the NHS, the National Institute for Health Research or the Department of Health. KR, IS, AF and CDB were supported by the National Institutefor Health Research (NIHR) Birmingham Biomedical Research Centre.

Competing interests MRD, PS, KP, AK-V and JLM are employed by IONTAS. EC and PH are employed by Nascient. KSM is a founder and director of Nascient Ltd. AF has received research funding from Roche and Pfizer. KR has received research funding from Abbvie and Pfizer and honoraria/consultancy fees from Lilly, BMS,UCB, Pfizer, Janssen and Roche Chugai. JLM is currently funded by Roche Holding AG. BDM was partly supported by the SGC, which is a registered charity (number1097737) that receives funds from AbbVie, Bayer Pharma AG, Boehringer Ingelheim, Canada Foundation for Innovation, Eshelman Institute for Innovation, Genome Canada through Ontario Genomics Institute (OGI-055), Innovative Medicines Initiative (EU/ EFPIA) (ULTRA-DD grant no. 115766), Janssen, Merck KGaA, Darmstadt, Germany, MSD, Novartis Pharma AG, Ontario Ministry of Research, Innovation and Science (MRIS), Pfizer, Sao Paulo Research Foundation - FAPESP, Takeda and Wellcome (106169/ZZ14/Z).

Patient consent for publication Not required.

Provenance and peer review Commissioned; internally peer reviewed.

(C) Author(s) (or their employer(s)) 2020. No commercial re-use. See rights and permissions. Published by BMJ.

\section{Check for updates}

To cite Aungier S, Cartwright AJ, Schwenzer A, et al. Ann Rheum Dis 2020;79:e43.

Received 28 January 2019

Accepted 30 January 2019

Published Online First 12 February 2019

\section{Linked}

- https://doi.org/10.1136/annrheumdis-2019-215063

Ann Rheum Dis 2020;79:e43. doi:10.1136/annrheumdis-2019-215108

ORCID iD

Kim S Midwood http://orcid.org/0000-0002-8813-2977

\section{REFERENCES}

1 Cutolo M, Soldano S, Paolino S. Potential roles for tenascin in (very) early diagnosis and treatment of rheumatoid arthritis. Ann Rheum Dis 2020;79:e42.

2 Aungier SR, Cartwright AJ, Schwenzer A, et al. Targeting early changes in the synovial microenvironment: a new class of immunomodulatory therapy? Ann Rheum Dis 2019:78:186-91.

3 Cutolo M, Picasso M, Ponassi M, et al. Tenascin and fibronectin distribution in human normal and pathological synovium. J Rheumatol 1992;19:1439-47. 